\title{
Incidence of Orofacial Clefts in Kumasi, Ghana
}

\author{
P. Agbenorku, ${ }^{1,2,3,4}$ M. Yore, ${ }^{5}$ K. A. Danso, ${ }^{2,3,4,6}$ and C. Turpin ${ }^{2,3,4,6}$ \\ ${ }^{1}$ Reconstructive Plastic Surgery and Burns Unit, Department of Surgery, Ghana \\ ${ }^{2}$ Komfo Anokye Teaching Hospital, Ghana \\ ${ }^{3}$ School of Medical Sciences, Ghana \\ ${ }^{4}$ Kwame Nkrumah University of Science \& Technology, Kumasi, Ghana \\ ${ }^{5}$ Thomas J. Watson Foundation, New York, NY 1007, USA \\ ${ }^{6}$ Department of Obstetrics \& Gynaecology, Ghana
}

Correspondence should be addressed to P. Agbenorku; pimagben@yahoo.com

Received 25 March 2013; Accepted 23 April 2013

Academic Editors: R. L. Bang and A. S. Halim

Copyright (C) 2013 P. Agbenorku et al. This is an open access article distributed under the Creative Commons Attribution License, which permits unrestricted use, distribution, and reproduction in any medium, provided the original work is properly cited.

\begin{abstract}
Background. Cleft lip and cleft palate are among the most common orofacial congenital anomalies. This study is to establish Orofacial Clefts Database for Kumasi, Ghana, with a view to extend it to other cities in future to obtain a national orofacial anomaly database. Methods. A descriptive prospective survey was carried out at eleven selected health facilities in Kumasi. Results. The total number of live births recorded was 27,449. Orofacial anomalies recorded were 36, giving an incidence of 1.31/1000 live births or 1 in 763 live births. The mean maternal age of cleft lip/palate babies was 29.85 years (range $18-40$ years). The male : female ratio for the orofacial anomalies babies was $1.3: 1$; the male : female ratio was $0.5: 1$ in the cleft lip group, $1.3: 1$ in the cleft lip and palate group, and $4: 1$ in the cleft palate group. The majority of clefts were unilateral $(69.4 \%, n=25)$, with females $(n=14)$ outnumbering males $(n=11)$. A family history of cleft was recorded with five babies (13.9\%). Associated congenital anomalies were recorded in seven (19.4\%) cleft lips and/or palates. Conclusion. The incidence of 1 in 763 live births found in this study indicates that cleft lip/palate is a common congenital anomaly in Kumasi.
\end{abstract}

\section{Introduction}

Orofacial clefts (OCs) are among the most common congenital facial anomalies. They result from a failed fusion of the medial, lateral, and maxillary processes, which normally occurs between the 6th and 10th weeks of intrauterine life. OCs can appear as an isolated anomaly or as a part of a multiple congenital anomaly accompanied by other noncleft malformations. OCs can appear as an isolated anomaly or as a part of multiple congenital noncleft malformations. Both genetic and environmental factors are known to contribute to these congenital malformations [1].

Cleft lip (CL), cleft palate (CP), or both (CLP) are the most common orofacial congenital malformations found among live births [2]. They account for $65 \%$ of all head and neck anomalies [3]. It is estimated that OCs occur in $\sim 1 / 700$ to $\sim 1 / 1000$ live births in different populations around the world and that there is substantial variability related to geographic origin, ethnicity, and socioeconomic conditions
$[4,5]$. Although some of these variations can be attributed to differences in the classification of OCs, populations of Asian or Native American origin tend to show the highest prevalence, with Caucasian populations showing the intermediate and African populations the lowest prevalence [6, 7]. Most studies of African populations have reported isolated cleft lip as the most common cleft type and CP as the least [8], which may represent a departure from the pattern of clefts reported for non-African populations, where CLP and CP are most common [9].

There are several reports regarding OC incidence, prevalence, disparities, and long-term patterns in Ghana; however, the findings have been inconsistent [10-12]. The inconsistency may be explained in part by unclear classification of clefts and syndromic status, differences in the underlying population, and geographic coverage and time span. These limitations made it previously impractical to achieve a comprehensive profile of OCs at the national level. 
In Ghana, OCs constitute a cause of perinatal death [13]. The survivors usually suffer from difficulties in feeding, swallowing, speaking, and hearing. In addition, children with OCs often face problems in cognition, communication, and education. It is desirable to better understand the current burden of OCs in the Ghanaian population and to provide new insights into incidence and demographic factors associated with the orofacial defect so that relevant health and social services can better reach those who need them most.

Surveillance systems usually involve health workers trained to identify and report occurrences of one or more medical conditions within a patient population. These systems provide information that can help health service administrators to better understand the burden of and plan adequate resources to manage a medical condition in a community. In addition, an increased awareness of the medical condition among health workers which often arises from training associated with the surveillance program could lead to earlier diagnosis and treatment and to improved long-term health outcomes for affected patients. In addition to provide information about OCs in a cross section of newborns in Kumasi, Ghana, the surveillance system used in this study to detect OCs may serve as a model for effective surveillance of OCs and other congenital anomalies in other resource-limited settings.

\section{Materials and Methods}

2.1. Study Setting. Kumasi is in the transitional forest zone of Ghana and is about $270 \mathrm{~km}$ north of the national capital, Accra. It has an area of about 254 square kilometres. The metropolitan area shares boundaries with Kwabre East District to the north, Atwima District to the west, Ejisu-Juaben Municipal to the east, and Bosomtwe to the south. The city is a rapidly growing one with an annual growth rate of $5.4 \%$. It encompasses about 90 suburbs, many of which were absorbed into it as a result of the process of growth and physical expansion. The 2010 Population Census gives the population as 2,170,070 [14]. The highest proportions of the population are in the age cohorts $0-4$ years $(13.2 \%)$ and 5-9 years (12.4\%). Cumulatively, $39.9 \%$ of the population is below 15 years, in contrast to other districts with corresponding figures which range from 40 to 47 percent.

This may be an indication of a slow, incipient decline in fertility. There are more males (50.2\%) than females (48.8\%) in the metropolis. The city has a number of health facilities in both the public and private sectors. Notable among them are the Komfo Anokye Teaching Hospital (KATH), which is one of the two national autonomous hospitals, four quasihealth institutions, and five healthcare centres owned by religious organizations. In addition, there are over 200 private health institutions and 13 industrial clinics in the metropolis. There are also 54 trained Traditional Birth Attendants (TBAs), nine Maternal and Child Health (MCH) points, and 119-outreach sites. These facilities are evenly distributed in space [14].

2.2. Patient Management. The corrective surgery for cleft lip can be performed at any time after the child is born. In general, providers follow the "Rule of 10 ". That is, babies are operated on at about 10 weeks old, with body weight about $10 \mathrm{lb}(4.5 \mathrm{~kg})$ and hemoglobin level of about $10.0 \mathrm{~g} / \mathrm{dL}$. The risks in general anesthesia are much reduced when these parameters are attained. Cleft palates are customarily repaired at about 12 months of age. For the children in this study who were diagnosed with CL and/or CP, Millard's rotation-advancement repair, straight-line procedure, and the Langenbeck variant methods were the surgical techniques used for unilateral CL, bilateral CL, and CP, respectively. Some babies with OCs from the study are shown in Figures 1 and 2.

2.3. Ethical Clearance. The Committee on Human Research, Publications and Ethics, School of Medical Sciences, Kwame Nkrumah University of Science and Technology/Komfo Anokye Teaching Hospital, Kumasi, gave the approval for this work.

2.4. Data Collection. This descriptive prospective survey was carried out between October 1, 2009 and September 30, 2010. The city was portioned into six parts, and three were selected for the study coverage. Health facilities that provide $\mathrm{MCH}$ services in the selected zone were also randomly selected for the study. In all, eleven health facilities (KATH, Tafo Government Hospital, Manhyia District Hospital, South Suntreso Hospital, Kumasi South Hospital, KNUST Hospital, Kezia Maternity Home and Clinic, Baby Pearl Maternity Home and Clinic, Mamie Maternity, Bomso Clinic, and Kumasi Children's Hospital) were involved in the study. All live births in the study health facilities were evaluated by trained staffs for the presence of cleft lip and/or palate and other related congenital anomalies. Sociodemographic data were obtained after respondents (mothers) had given their consent for the study. Information obtained included family history of CL/CP or CLP.

2.5. Limitation of Study. Only a section of health delivery centers in Kumasi was involved in the study; hence, the sample size was small.

2.6. Statistical Analysis. The data was collected using a pretested study questionnaire. Descriptive results were depicted with tables and figures. Multiple regression analysis was used to determine possible demographic risk factors. SPSS statistical software version 16 [15] was used for the data analysis. A probability value $(P$ value) of less than 0.05 was considered to be statistically significant.

\section{Results}

3.1. Incidence. The total number of live births recorded in the study institutions was 27,449. Orofacial anomalies recorded were 36 ; this gives an incidence of 1.31/1000 live births or 1 in 763 live births. The mean maternal age of cleft lip/palate babies was 29.85 years (range 18-40 years). A family history of OCs was recorded in 5 (13.9\%) babies (Figure 3). 


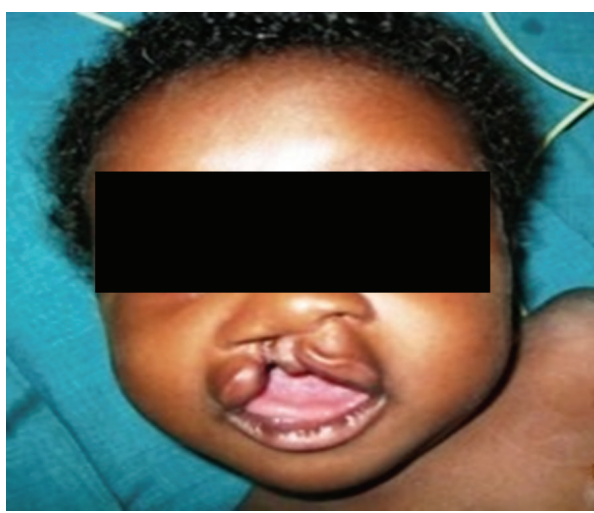

(a) Before surgery

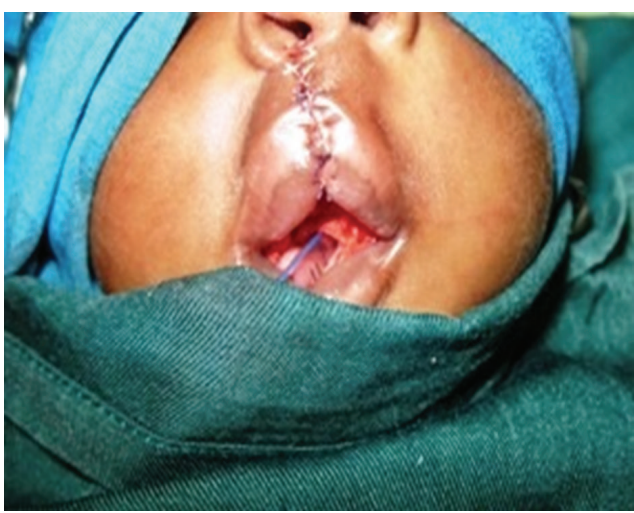

(b) After surgery, lip repair

Figure 1: A baby with cleft lip (right unilateral, complete).

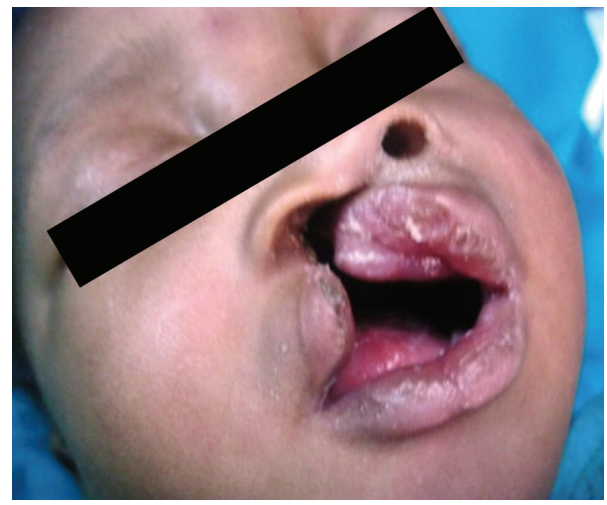

(a) Before surgery

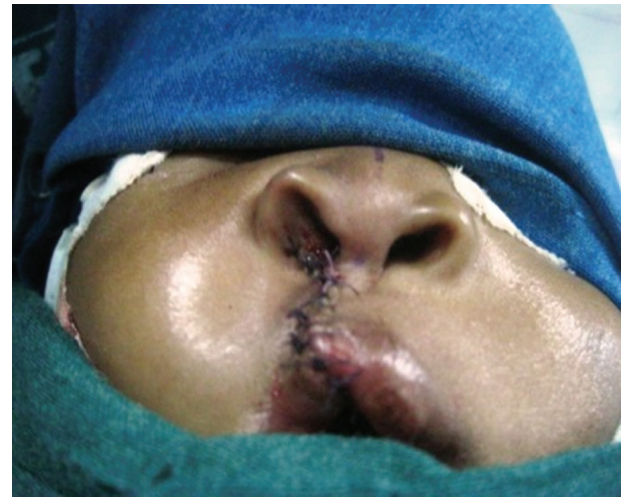

(b) After surgery, lip repair

Figure 2: A baby with cleft lip and palate (right unilateral, complete).

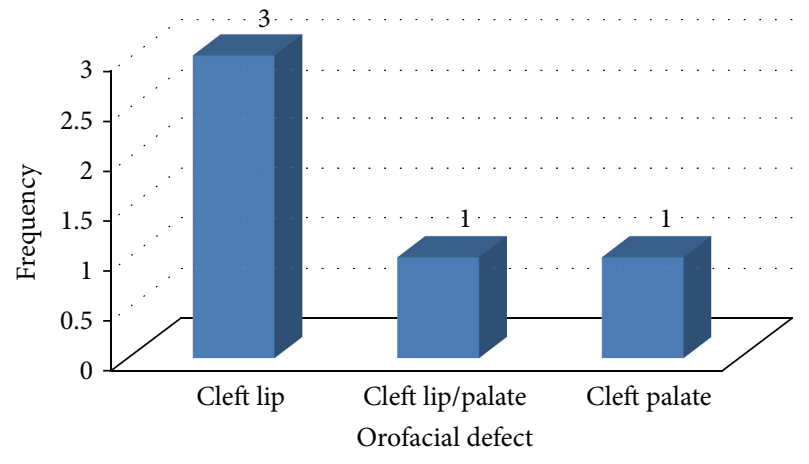

FIGURE 3: Family history of orofacial clefts recorded in the study.

Associated congenital anomalies were recorded in a few $(19.4 \%, n=7)$ cleft babies: spina bifida (neural tube defect) in 1 , cri-du-chat in 1, extremity malformation in 4 (Syndactyly in 3 , popliteal webbing polydactyly in 1 ), and an imperforate anus.

The male: female ratio for the orofacial anomalies babies was $1.3: 1$; the male: female ratio was $0.5: 1$ in the cleft lip

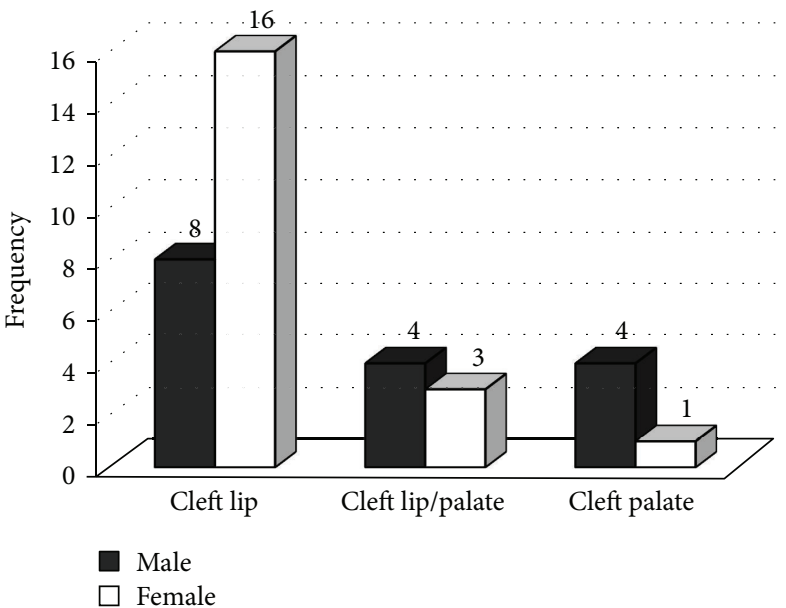

Figure 4: Types of orofacial clefts and the corresponding sex ratio.

group, $1.3: 1$ in the cleft lip and palate group, and $4: 1$ in the cleft palate group (Figure 4). 
TABLE 1: Types of orofacial clefts detected in the study population.

\begin{tabular}{lc}
\hline Category & Number $(\%)$ \\
\hline Unilateral cleft lip \pm alveolus & $21(58.3)$ \\
Bilateral cleft lip \pm alveolus & $3(8.3)$ \\
Unilateral cleft lip and palate & $4(11.2)$ \\
Bilateral cleft lip and palate & $3(8.3)$ \\
Cleft hard and soft palate & $3(8.3)$ \\
Isolated cleft of soft palate & $2(5.6)$ \\
\hline Total & $36(100.0)$ \\
\hline
\end{tabular}

3.2. Types of Orofacial Clefts among Babies. Cleft lip and/or alveolus only $(66.7 \%, n=24)$ was the highest type of orofacial cleft recorded in the study, followed by CLP $(19.4 \%, n=7)$ as shown in Table 1.

3.3. Occurrence and Position of Orofacial Clefts among Babies. Orofacial clefts were categorized taking into consideration its occurrence (whether cleft is complete or incomplete) and position. In terms of occurrence, complete cleft $(63.9 \%$, $n=23$ ) outnumbered the incomplete types; for position, unilateral clefts were the most common $(36.1 \%, n=14)$, as shown in Table 2.

3.4. Association between Orofacial Clefts and Demographic Features. Multiple regression analysis was performed to determine if certain demographic features were associated with specific OC types.

Demographic parameters modeled were maternal age, family history, associated congenital anomalies, and sex of babies; characteristics of the cleft used included: type, occurrence, and position. The analysis reveals a significant association between parameters such as maternal age, male sex, and cleft lips (Table 3).

\section{Discussion}

A review of the studies for incidence of $\mathrm{CL} / \mathrm{P}$ shows that there is no particular trend in different parts of the world. A WHO published study, Global Strategies to Reduce the Health Care Burden of Craniofacial Anomalies, details the incidence OCs in 13 countries. According to this study, the incidence varies from 0.22 to 1.67 per 1000 live births [16]. The incidence of OCs shows ethnic variation. It is generally thought that populations of Asian or Native North American descent have the highest incidence, with Caucasian populations having intermediate incidence and African populations having the lowest incidence [17].

In studies conducted on a Caucasian population, the incidence of clefts in Northern Ireland was found to be 1.28 for every 1000 live births [18]. The incidence of cleft defects in the Stockholm County in Sweden was found to be 2.0:1000 live births [19]. In Latin America, a study in Northeast Mexico showed an incidence of clefts to be 1.1: 1000 live births [20], In Asia, a study of a Han Chinese population in Shanghai, China, showed an incidence of 1.12 per 1000 live births [21]. A study of a native Filipino population reported that the incidence was higher at 1.54 in 1000 live births [22], whilst a study in Iran showed an incidence of 1.03:1000 live births [23]. An Indian study showed an incidence of 1.09 in 1000 live births [24]. Reports from different African populations vary widely, from as low as 0.3/1,000 reported in Nigeria [25] to 1.65/1,000 reported in Kenya [26]. This study has showed an incidence of 1.31 per 1000 live births.

The difference in incidence among Whites and Blacks in different geographical locations may be due to differences in genetic and environmental causal factors. The aetiology of $\mathrm{OC}$ is thought to involve genetic predisposition coupled with environmental factors. The low incidence figure of $0.41 / 1,000$ reported in a study in India [27] is similar to rates reported in studies in Africa. Both places are low income countries, and there is the possibility of under reporting of $\mathrm{OC}$ cases. Caution must also be taken when comparing rates of other continents to Africa because of the differences in the methods of capture of cases.

Many studies report a male predominance in the sex ratio in $\mathrm{CL} / \mathrm{CP}$ patients and a female predominance in patients with CP only defects $[24,28]$. However, in this study, males showed an unusually high predominance for CP. Male predominance for cleft lip and palate was also confirmed by the study indicating that there was a greater possibility of a male child being born with a CL/CP in Ghana.

Many studies give a ratio between unilateral and bilateral cleft lips to be predominantly favouring unilateral cleft lips $[24,29]$. We found that $69.4 \%,(n=25)$ of the clefts defects were unilateral in nature. It is also widely accepted that leftsided unilateral clefts are more common than right-sided unilateral cleft lips $[24,28]$, which is not supported by this study. This study revealed that $38.9 \%$ of the unilateral CL was right sided. The discrepancies in our results needs to be further investigated for any extraneous circumstances.

Several studies have reported increased risk of OCs with increased maternal age [30]. However, larger studies failed to identify advanced maternal age as a risk factor for OCs $[31,32]$. Conversely, other studies found a greater risk for $\mathrm{CL}$ among younger mothers [33, 34]. Infant sex influences the risk for OCs. Males are more likely than females to have a CL with or without CP, while females are at slightly greater risk for CP alone $[20,30]$. One study indicated that family history of clefts, birth order, maternal age at birth, first-trimester maternal smoking, and alcohol consumption during pregnancy did not explain the sex difference [31]. Infants born with other malformations such as those involving the respiratory system, eyes, ears, upper alimentary tract, and other musculoskeletal anomalies are at increased risk for having CL and/or CP [35]. Additionally, infants with OCs were more likely to have congenital heart disease; however, these diseases were more likely to be associated with a syndrome than with an isolated cleft [34]. Other malformations associated with clefting include respiratory system defects [30].

This study found that maternal age is a risk factor for unilateral right $\mathrm{CL}(P=0.033)$. In addition, being male is a risk factor for bilateral cleft $(P=0.045)$. Thus, in areas where OCs are prevalent in developing countries such 
TABLE 2: Characteristics of orofacial clefts among the babies.

\begin{tabular}{lccccccc}
\hline \multirow{2}{*}{ Cleft } & \multirow{2}{*}{ Frequency $(n)$} & \multicolumn{2}{c}{ Occurrence } & \multicolumn{3}{c}{ Position } \\
& & Complete & Incomplete & Unilateral CP & Bilateral & Unilateral right & Unilateral left \\
\hline Cleft lip & 24 & 16 & 8 & - & 3 & 10 & 11 \\
Cleft palate & 5 & 0 & 5 & 5 & 0 & - & - \\
Cleft lip/palate & 7 & 7 & 0 & - & 3 & 4 & 0 \\
\hline
\end{tabular}

TABLE 3: A summary of multiple regression analysis of demographics and cleft features.

\begin{tabular}{lccccc}
\hline & Unilateral CL & Bilateral CL & Unilateral CP & Unilateral CL/CP & Bilateral CL/CP \\
\hline Maternal age & $0.033^{*}$ (right) & 0.087 & 0.500 & 2.023 & 0.335 \\
Family history & 0.899 & 0.604 & 0.352 & 1.553 & 0.654 \\
Associated congenital anomalies & 0.401 & 1.052 & 0.320 & 0.960 & 0.085 \\
Male & 0.0621 & $0.045^{*}$ & 0.900 & 0.999 & 0.594 \\
Female & 0.210 & 0.177 & 0.650 & 0.057 & 0.350 \\
\hline
\end{tabular}

${ }^{*}$ It donates significant value $(P<0.05)$.

as Ghana, it may be recommended that detailed ultrasonographic investigation of foetus for OCs should be considered, especially for older pregnant patients and those carrying a male fetus. Adopting more comprehensive prenatal screening practices will allow healthcare providers greater opportunity to educate and counsel involved parents on how to feed and care for their newborn before surgical repair of the cleft. Determining the exact incidence of OCs in Africa is important for public health reasons, as documentation of the incidence rates will help identify cluster areas and possible etiological factors, which will in turn help governments plan strategies for preventive measures and treatment.

\section{Conclusion}

This study has found the incidence of cleft congenital anomalies in Kumasi to be 1.31/1000 live births. Maternal age and the male sex were found to be major risk factors. Since many babies in Ghana, as in many Africa countries, are born outside hospitals, the incidence of clefts determined in this study could be an underestimate. Health planners should therefore give attention to cleft care in Ghana and Africa as a whole by promoting cleft awareness programs.

\section{Recommendation}

Health policy makers should put measures in place to treat patients with the condition; also, health education in order to create awareness on the condition should be encouraged, and, finally, there should be more studies carried out in this field.

\section{Conflict of Interests}

The authors declare no conflicts of interest.

\section{Acknowledgment}

The authors sincerely thank Mr. Frank Ocloo for actively helping to collect the data that formed the basis of this paper.
The authors are very much grateful to the various institutions that took part in this study.

\section{References}

[1] J. C. Murray, "Gene/environment causes of cleft lip and/or palate," Clinical Genetics, vol. 61, no. 4, pp. 248-256, 2002.

[2] V. P. Singh, J. N. Sharma, D. K. Roy et al., "A study of orofacial clefts seen in a tertiary referral hospital in Nepal," Ceylon Medical Journal, vol. 57, no. 2, pp. 84-85, 2012.

[3] R. J. Gorlin, M. M. Cohen, and R. C. M. Hennekam, Syndromes of the Head and Neck, Oxford University Press, Oxford, UK, 4th edition, 2001.

[4] P. A. Mossey and J. Little, "From origins to treatment," in Epidemiology of Oral Clefts: An International Perspective, in Cleft Lip And Palate, D. F. Wyszynski, Ed., pp. 127-158, Oxford University Press, Oxford, UK, 2002.

[5] A. P. Vanderas, "Incidence of cleft lip, cleft palate, and cleft lip and palate among races: a review," Cleft Palate Journal, vol. 24, no. 3, pp. 216-225, 1987.

[6] L. A. Croen, G. Shaw, C. R. Wassermann, and M. M. Tolarova, "Racial and ethnic variations in the prevalence of orofacial clefts in California, 1983-1992," American Journal of Medical Genetics, vol. 79, pp. 42-47, 2000.

[7] K. K. H. Gundlach and C. Maus, "Epidemiological studies on the frequency of clefts in Europe and world-wide," Journal of Cranio-Maxillofacial Surgery, vol. 34, no. 2, pp. 1-2, 2006.

[8] R. F. Elliott, G. Jovic, and M. Beveridge, "Seasonal variation and regional distribution of cleft lip and palate in Zambia," Cleft Palate-Craniofacial Journal, vol. 45, no. 5, pp. 533-538, 2008.

[9] R. A. Spritz, T. D. Arnold, S. Buonocore et al., "Distribution of orofacial clefts and frequent occurrence of an unusual cleft variant in the Rift Valley of Kenya," Cleft Palate-Craniofacial Journal, vol. 44, no. 4, pp. 374-377, 2007.

[10] P. Agbenorku, M. Agbenorku, R. Sefenu et al., "Endemicity of cleft lip/palate in a rural community in South-East Ghana," Journal of Science Technology, vol. 27, pp. 45-50, 2007.

[11] P. Donkor, D. O. Bankas, P. Agbenorku, G. Plange-Rhule, and S. K. Ansah, "Cleft lip and palate surgery in Kumasi, Ghana: 20012005," Journal of Craniofacial Surgery, vol. 18, no. 6, pp. 13761379, 2007. 
[12] A. Butali and P. A. Mossey, "Epidemiology of orofacial clefts in Africa: methodological challenges in ascertainment," Pan African Medical Journal, vol. 1, pp. 5-14, 2009.

[13] P. Agbenorku, S. Ansah, A. Acheampong et al., "Komfo Anokye Teaching Hospital multidisciplinary cleft clinic," Journal of Craniofacial Surgery, vol. 22, no. 2, pp. 532-536, 2011.

[14] Kumasi Metropolitan Assembly, July 2010, http://www.ghanadistricts.com/districtslonl/kma/?read=41995\&print.

[15] SPSS (Computer Program) Version 16, SPSS Inc., Chicago, Ill, USA, 2006.

[16] Global Strategies to Reduce the Health Care Burden of Craniofacial Anomalies. Report of WHO Meetings on International Collaborative Research on Craniofacial Anomalies, Geneva, Switzerland, 2000.

[17] R. J. Gorlin, M. M. Cohen, and R. C. Hennekam, Monographs on Medical Genetics Syndromes of the Head and Neck, Oxford University Press, Oxford, UK, 2001.

[18] T. Gregg, D. Boyd, and A. Richardson, "The incidence of cleft lip and palate in Northern Ireland from 1980-1990," British Journal of Orthodontics, vol. 21, no. 4, pp. 387-392, 1994.

[19] C. Hagberg, O. Larson, and J. Milerad, "Incidence of cleft lip and palate and risks of additional malformations," Cleft Palate Craniofacial Journal, vol. 35, pp. 40-45, 1998.

[20] F. Blanco-Davila, "Incidence of cleft lip and palate in the northeast of Mexico: a 10-year study," The Journal of Craniofacial Surgery, vol. 14, no. 4, pp. 533-537, 2003.

[21] M. E. Cooper, J. S. Ratay, and M. L. Marazita, "Asian oral-facial cleft birth prevalence," Cleft Palate-Craniofacial Journal, vol. 43, no. 5, pp. 580-589, 2006.

[22] J. C. Murray, S. Daack-Hirsch, K. H. Buetow et al., "Clinical and epidemiological studies of cleft lip and palate in the Philippines," Cleft Palate Craniofacial Journal, vol. 34, pp. 7-10, 1997.

[23] M. H. Rajabian and M. Sherkat, "An epidemiologic study of oral clefts in Iran: analysis of 1669 cases," Cleft Palate-Craniofacial Journal, vol. 37, no. 2, pp. 191-196, 2000.

[24] S. G. Reddy, R. R. Reddy, E. M. Bronkhorst et al., "Incidence of cleft Lip and palate in the state of Andhra Pradesh, South India," Indian Journal of Plastic Surgery, vol. 43, no. 2, pp. 184-189, 2010.

[25] L. M. Iregbulem, "The incidence of cleft lip and palate in Nigeria," Cleft Palate Journal, vol. 19, no. 3, pp. 201-205, 1982.

[26] A. A. Khan, "Congenital malformations in African neonates in Nairobi," Journal of Tropical Medicine and Hygiene, vol. 68, no. 11, pp. 272-274, 1965.

[27] “Census of India," New Delhi: Census India, 2001, http://www .censusindia.net.

[28] P. Fogh-Andersen, "Epidemiology and etiology of clefts," Birth Defects Original Article Series, vol. 7, no. 7, pp. 50-53, 1971.

[29] F. E. Abyholm, "Cleft lip and palate in Norway. I. Registration, incidence and early mortality of infants with CLP," Scandinavian Journal of Plastic and Reconstructive Surgery, vol. 12, no. 1, pp. 29-34, 1978.

[30] G. M. Shaw, H. Zhu, E. J. Lammer, W. Yang, and R. H. Finnell, "Genetic variation of infant reduced folate carrier (A80G) and risk of orofacial and conotruncal heart defects," American Journal of Epidemiology, vol. 158, no. 8, pp. 747-752, 2003.

[31] S. Abramowicz, M. E. Cooper, K. Bardi, R. J. Weyant, and M. L. Marazita, "Demographic and prenatal factors of patients with cleft lip and cleft palate: a pilot study," Journal of the American Dental Association, vol. 134, no. 10, pp. 1371-1376, 2003.
[32] L. D. Vallino-Napoli, M. M. Riley, and J. Halliday, "An Epidemiologic Study of Isolated Cleft Lip, Palate, or Both in Victoria, Australia from 1983 to 2000," Cleft Palate-Craniofacial Journal, vol. 41, no. 2, pp. 185-194, 2004.

[33] L. A. DeRoo, J. A. Gaudino, and L. D. Edmonds, "Orofacial cleft malformations: associations with maternal and infant characteristics in Washington State," Birth Defects Research Part A, vol. 67, no. 9, pp. 637-642, 2003.

[34] J. Reefhuis and M. A. Honein, "Maternal age and non-chromosomal birth defects, Atlanta-1968-2000: teenager or thirtysomething, who is at risk?" Birth Defects Research Part A, vol. 70, no. 9, pp. 572-579, 2004.

[35] G. M. Shaw, V. Nelson, S. L. Carmichael, E. J. Lammer, R. H. Finnell, and T. H. Rosenquist, "Maternal periconceptional vitamins: interactions with selected factors and congenital anomalies?” Epidemiology, vol. 13, no. 6, pp. 625-630, 2002. 


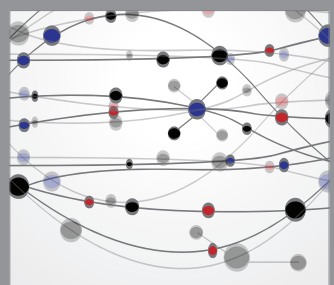

The Scientific World Journal
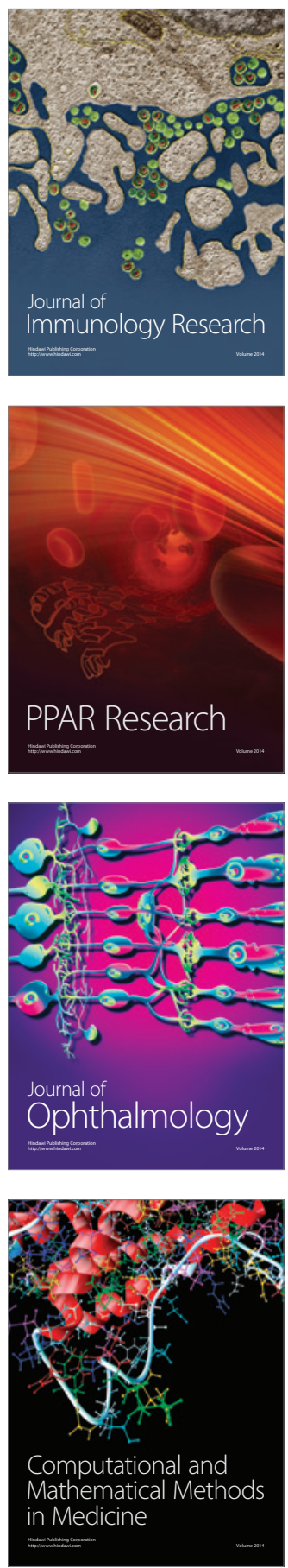

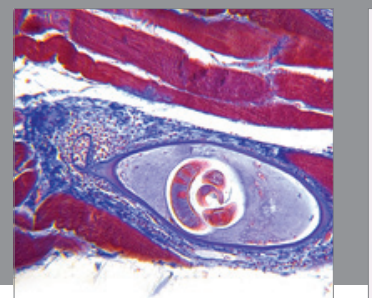

Gastroenterology

Research and Practice
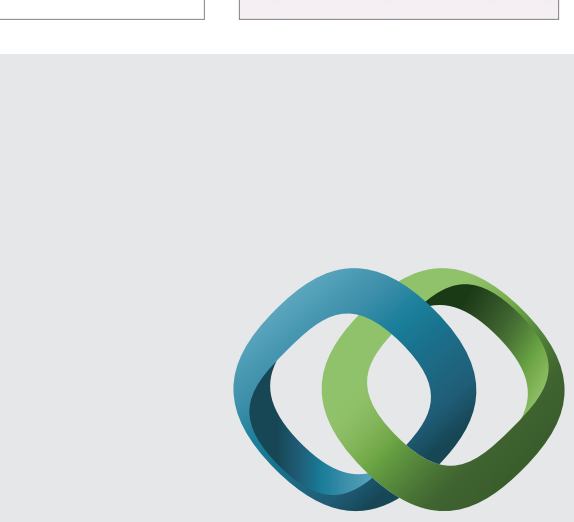

\section{Hindawi}

Submit your manuscripts at

http://www.hindawi.com
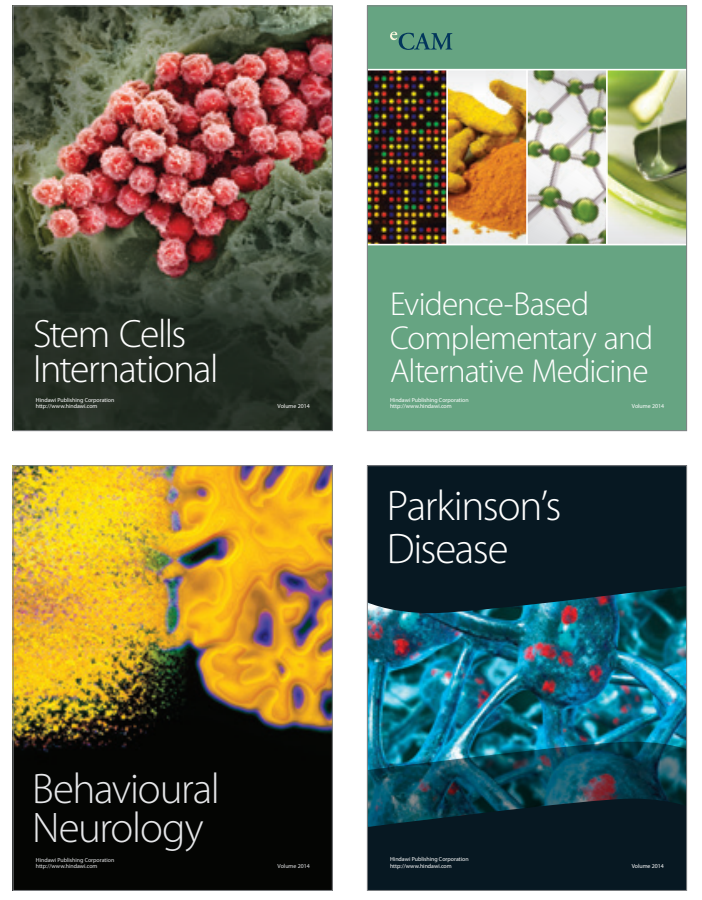
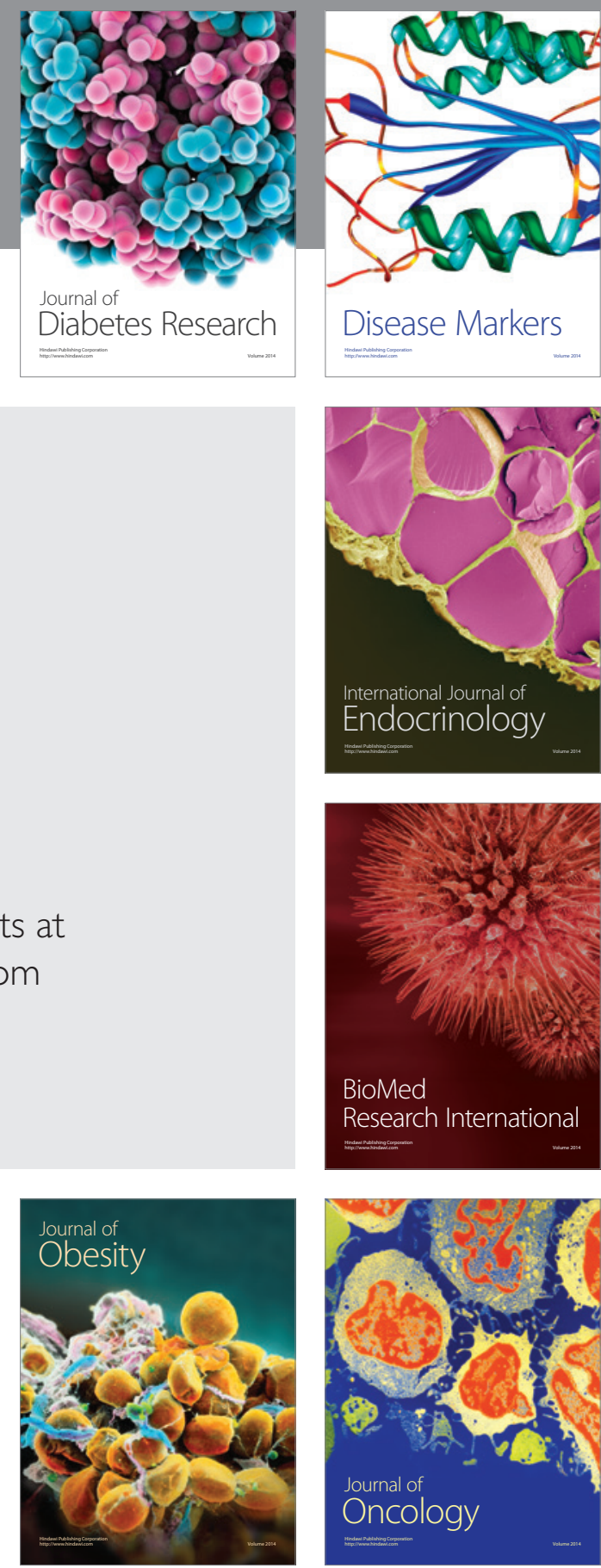

Disease Markers
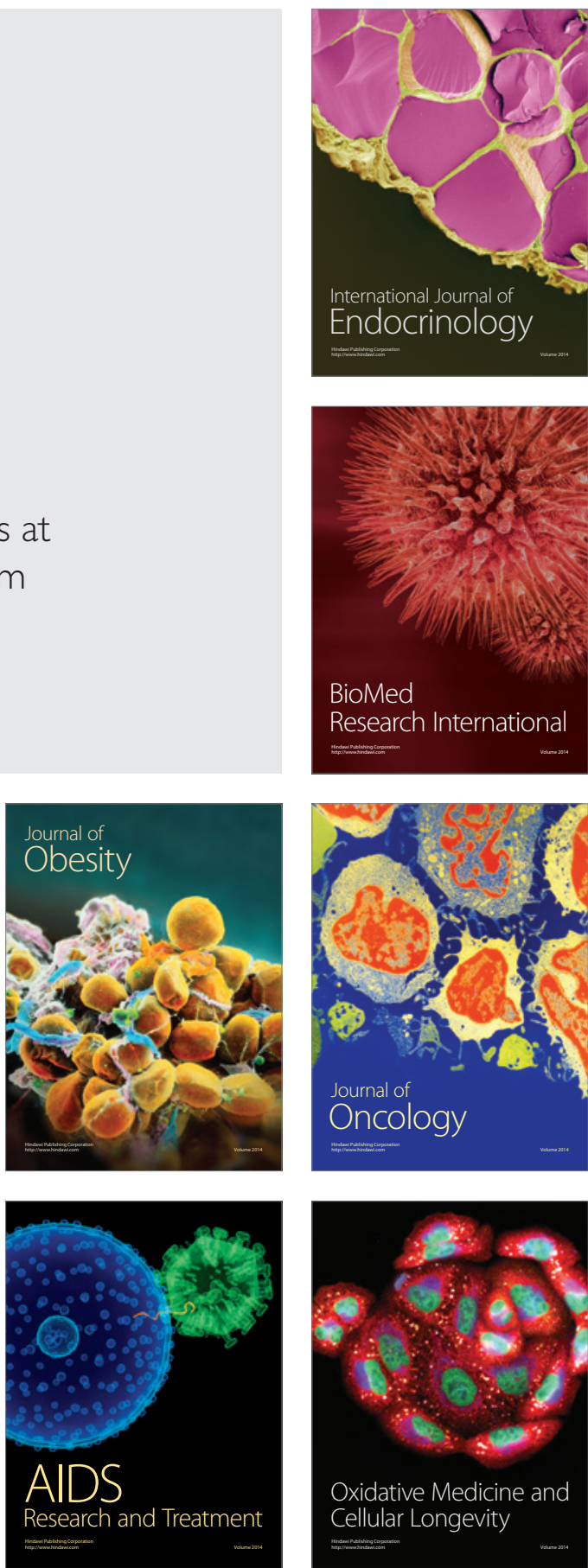